OPEN ACCESS

Edited by:

Tatiana Venkova,

University of Texas Medical Branch,

United States

Reviewed by:

Maite Muniesa,

University of Barcelona, Spain

Elisabeth Grohmann,

Beuth University of Applied Sciences,

Germany

*Correspondence:

Silvia Ayora

sayora@cnb.csic.es

${ }^{\dagger}$ These authors have contributed equally to this work.

Specialty section:

This article was submitted to

Evolutionary and Genomic

Microbiology

a section of the journal

Frontiers in Microbiology

Received: 18 July 2017 Accepted: 06 September 2017

Published: 22 September 2017

Citation:

Valero-Rello A, López-Sanz M, Quevedo-Olmos A, Sorokin A and

Ayora S (2017) Molecular

Mechanisms That Contribute to Horizontal Transfer of Plasmids by

the Bacteriophage SPP1

Front. Microbiol. 8:1816.

doi: 10.3389/fmicb.2017.01816

\section{Molecular Mechanisms That Contribute to Horizontal Transfer of Plasmids by the Bacteriophage SPP1}

\author{
Ana Valero-Rello ${ }^{1,2+}$, María López-Sanz ${ }^{1 \dagger}$, Alvaro Quevedo-Olmos ${ }^{1}$, Alexei Sorokin ${ }^{2}$ and \\ Silvia Ayora ${ }^{1 *}$
}

1 Department of Microbial Biotechnology, Centro Nacional de Biotecnología, Consejo Superior de Investigaciones Cientificas, Madrid, Spain, ${ }^{2}$ Micalis Institute, INRA, AgroParisTech, Universite Paris-Saclay, Jouy-en-Josas, France

Natural transformation and viral-mediated transduction are the main avenues of horizontal gene transfer in Firmicutes. Bacillus subtilis SPP1 is a generalized transducing bacteriophage. Using this lytic phage as a model, we have analyzed how viral replication and recombination systems contribute to the transfer of plasmid-borne antibiotic resistances. Phage SPP1 DNA replication relies on essential phage-encoded replisome organizer (G38P), helicase loader (G39P), hexameric replicative helicase (G4OP), recombinase (G35P) and in less extent on the partially dispensable $5^{\prime} \rightarrow 3^{\prime}$ exonuclease (G34.1P), the single-stranded DNA binding protein (G36P) and the Holliday junction resolvase (G44P). Correspondingly, the accumulation of linear concatemeric plasmid DNA, and the formation of transducing particles were blocked in the absence of G35P, G38P, G39P, and G40P, greatly reduced in the G34.1P, G36P mutants, and slightly reduced in G44P mutants. In contrast, establishment of injected linear plasmid DNA in the recipient host was independent of viral-encoded functions. DNA homology between SPP1 and the plasmid, rather than a viral packaging signal, enhanced the accumulation of packagable plasmid DNA. The transfer efficiency was also dependent on plasmid copy number, and rolling-circle plasmids were encapsidated at higher frequencies than theta-type replicating plasmids.

Keywords: horizontal gene transfer, plasmid transduction, SPP1, bacteriophages, antibiotic resistance

\section{INTRODUCTION}

Bacteriophage-mediated horizontal gene transfer enhances bacterial adaptive responses to environmental changes, and it is one of the mechanisms responsible for the rapid spread of antibiotic resistance, bacterial virulence and pathogenicity (Canchaya et al., 2003; Brussow et al., 2004; Brown-Jaque et al., 2015; Penades et al., 2015; Touchon et al., 2017). Bacteriophages, or simply phages, play active roles in the specialized mobilization of discrete chromosomal regions (specialized transduction), and also with significant efficiency can transfer any chromosomal segment or plasmid DNA (generalized transduction). The difference between these two transduction modes is that specialized transduction is the consequence of the faulty excision of the prophage from the bacterial chromosome, resulting into packaging of phage DNA as well as

Abbreviations: PFGE, pulsed field gel electrophoresis; RCR, rolling circle replication; SPP1, B. subtilis bacteriophage SPP1; sus, suppressor sensitive (mutation); TR, theta replication; ts, thermosensitive; wt, wild type. 
adjacent DNA from the bacterial chromosome (Canchaya et al., 2003; Brussow et al., 2004; Penades et al., 2015; Touchon et al., 2017). In generalized transduction, phage DNA mispackaging occurs, and the viral packaging machinery uses chromosomal or plasmid DNA as a substrate for DNA packaging into the empty proheads instead of viral DNA (Ikeda and Tomizawa, 1965; Viret et al., 1991). Generalized transduction, which is recognized as a widespread mechanism for the transfer of any gene from one bacterium to another, was originally reported in $\gamma$-proteobacteria (Zinder and Lederberg, 1952; Lennox, 1955), and it has been also reported in many Gram-positive pathogens (Maslanova et al., 2013; Giovanetti et al., 2014; Winstel et al., 2015). The majority of generalized transducing phages package their DNA by the headful packaging mechanism (pac phages). One remarkable event related to this, is the encapsidation of pathogenicity islands, as it occurs with the Staphylococcus aureus pathogenicity islands (SaPIs). SAPIs have developed elegant strategies to hijack the phage machinery to use it for their own transfer (Penades et al., 2015). Most SaPI helper phages identified to date are pac phages, and many well-studied SaPIs are packaged by the headful mechanism (Ruzin et al., 2001). Despite its importance in spreading antibiotic resistances and virulence, the mechanisms that occur inside the cell and lead to the erroneous encapsidation of foreign DNA upon phage infection remain largely unexplored.

SPP1 is a 44-kb virulent Bacillus subtilis phage that can carry out generalized transduction (plasmid and chromosomal) with a significant frequency (Yasbin and Young, 1974; Ferrari et al., 1978; Canosi et al., 1982). The SPP1 replication and packaging machineries have been studied in deep (Alonso et al., 2006; Lo Piano et al., 2011; Oliveira et al., 2013). SPP1 DNA replication starts by the theta mode when the replisome organizer, G38P, binds to the replication origin, oriL (Pedre et al., 1994; Missich et al., 1997; Seco and Ayora, 2017). Then, the phage helicase loader (G39P) recruits the replicative haxameric helicase (G40P). The viral helicase recruits the host-encoded primase (DnaG) and DnaX, which is a subunit of the clamp loader (Pedre et al., 1994; Ayora et al., 1999; Martinez-Jimenez et al., 2002), so that a full replisome is loaded at the phage origin. SPP1 replication uses the host replicase holoenzyme and topoisomerases from the host (Seco et al., 2013; Seco and Ayora, 2017). After one or two rounds of theta-type replication (TR), it shifts to concatemeric (sigmatype) DNA replication in a process driven by recombination (Lo Piano et al., 2011). Two viral proteins may participate in this shift, the ATP-independent single-strand annealing recombinase (G35P) and its partner, the $5^{\prime} \rightarrow 3^{\prime}$ exonuclease (G34.1P) (Ayora et al., 2002; Martinez-Jimenez et al., 2005). In the shift to concatemeric DNA replication, G38P, bound to oriR, or working as a pre-primosome organizer (like the bacterial PriA enzyme), may restart DNA replication at stalled or paused replication forks (Seco et al., 2013). SPP1 codes for two other proteins involved in DNA replication and recombination: the G36P and G44P proteins. G36P is a single-stranded DNA binding protein (SSB), and G44P is a Holliday junction resolvase of the RusA family, which recognizes and cleaves a variety of recombination intermediates (Martinez-Jimenez et al., 2005; Zecchi et al., 2012). Biochemical assays showed that G36P is crucial for SPP1 DNA replication in vitro, but it can be substituted by host-encoded SSB (known as SsbA) (Seco et al., 2013). The role of G44P in SPP1 replication is thought to be the processing of the stalled replication fork, which may trigger the shift to the sigma-type or concatemeric DNA replication. This type of DNA replication is essential to generate the concatemeric DNA, which is the substrate for encapsidation. Viral replication and packaging are sequential and in some way coupled events. SPP1 encapsidates linear double-strand (ds) DNA into an empty prohead by a processive ( $\sim 4$ sequential packaging cycles) headful packaging mechanism, using the linear head-to-tail concatemer as a substrate (Oliveira et al., 2013). This is consistent with the observation that an in vitro DNA packaging system efficiently packaged mature SPP1 DNA as well as linear plasmid DNA, but no DNA packaging could be detected when circular DNA was the substrate for encapsidation (Oliveira et al., 2005). SPP1 packaging is initiated with the recognition of the specific pac region by the terminase small subunit, G1P, and the sequence specific cleavage at the pac sequence (CTATTGCGG $\downarrow C$ ) by the terminase large subunit, G2P (Chai et al., 1992, 1995, 1997). This generates the first DNA end to be encapsidated (Chai et al., 1992; Gual et al., 2000; Camacho et al., 2003). A sequence independent cleavage, at $104 \%$ of the genome (headful cleavage), terminates one packaging round, generating a new starting point for another one (Chai et al., 1995; Camacho et al., 2003). Hence, the first cleavage in the concatemeric SPP1 DNA occurs specifically at pac, whereas the next ones do not (Gual et al., 2000).

In addition to package viral DNA, SPP1 is able to encapsidate chromosomal or plasmid DNA. However, some differences were observed with these two substrates. Rolling-circle replicating plasmids could be transduced at a frequency much higher than chromosomal DNA (Ferrari et al., 1978; Deichelbohrer et al., 1985), and an explanation for this could be that the copy number of plasmids in the cell is higher than that of the chromosome. Alternatively, another possibility could be that the replication mode influences the transduction frequency. It was also observed that the frequency of transduction of pUB110 and pC194 naturally occurring plasmids was enhanced 100 - to 1000 -fold by the presence of inserts homologous to the transducing phage DNA (Deichelbohrer et al., 1985). This homology-facilitated plasmid transduction was independent of the host RecA (Canosi et al., 1982; Deichelbohrer et al., 1985). In contrast, another report showed that SPP1 mediated chromosomal transduction was reduced 30-fold in cells having mutations in host functions involved in homologous recombination, such as $\operatorname{RecA}$, RecU, and RecF (Ferrari et al., 1978). These differences, which were observed between plasmid and chromosomal transduction in the SPP1 system motivated us to analyze in deep and throughout the manuscript the influence of the replication mode and of the plasmid copy number in plasmid generalized transduction. In addition, we have analyzed the role of phage recombination and replication proteins. We show that in absence of G35P, G38P, G39P, or G40P linear plasmid transduction is blocked. In contrast, establishment of injected linear plasmid DNA in the recipient host was independent of viral-encoded functions. The transfer efficiency was found to be dependent on homology to phage DNA, plasmid copy number, and replication mechanism. 


\section{MATERIALS AND METHODS}

\section{Bacterial Strains and Plasmids}

Bacillus subtilis BG214 (trpCE metA5 amyE1 ytsJ1 rsbV37 $x r e 1 \quad x k d \mathrm{~A} 1$ att ${ }^{\mathrm{SPB}} a t t^{\mathrm{ICEBsI}}$ ) and its isogenic derivative BG295 (sup3) were used. They lack the ICEBs1 integrative conjugative element as well as prophage PBSX, and PBSX prohage cannot be induced (Kidane et al., 2009). The plasmids used are derivatives of pHP13, pUB110, pBT233 or pNDH33 (Table 1). To construct pBT233N, the pUB110 neomycin resistance gene was cloned into AvaI-linearized pBT233. Different regions of the SPP1 genome were cloned into the HpaI site of the pBT233N plasmid as indicated in Table 1. pHP13 derivatives were kindly provided by J. C. Alonso (CNB-CSIC). Plasmid pBT400 is a pHP13 derivative bearing an EcoRI-SalI fragment of SPP1 DNA. Different SPP1 DNA fragments were cloned into XbaI- or SmaI-cleaved pNDH33 DNA, rendering pNDH33-1300 and pNDH33-pac (Table 1).

\section{SPP1 Phages}

The SPP1 phages used in this work are listed in Table 2, including those (sus19, sus53, sus109, tsB3, and SPP1 $\Delta \mathrm{A}$ ) previously described (Chai et al., 1992; Pedre et al., 1994; Zecchi et al., 2012).

The SPP1 tsI20F mutant was sequenced and it was found that the mutation that conferred thermosensitivity (ts), P159S, mapped in gene 35, rather than in gene 34.1, as it was previously suggested after genetic mapping (Burger and Trautner, 1978). This phage was used to construct the SPP1 sus 35 mutant. First, a lysine codon (the 10th codon in the gene 35 ) was replaced by an ochre (UAA) stop codon by site-directed mutagenesis using plasmid pCB610 as template (a pHP13 derivative containing SPP1 genes 34.4 to 35 ) and the Quickchange protocol. After sequencing confirmation the resulting plasmid (pHP13-G35Pochre) was introduced into BG295 cells by transformation. BG295 cells bearing pHP13-G35P-ochre plasmid were infected with SPP1 tsI20F phage at $30^{\circ} \mathrm{C}$ for $2 \mathrm{~h}$. The resulting phage lysate was used to infect BG295 cells at non-permissive temperature to

TABLE 1 | Plasmids used in this work.

\begin{tabular}{lll}
\hline Plasmids & Plasmid characteristics & Reference \\
\hline pC194 & Natural rolling circle replicating (RCR) plasmid, 2.9-kb & Horinouchi and Weisblum, 1982; \\
& & Alonso and Trautner, 1985 \\
pHP13 & RCR plasmid derivative of pTA1060, 4.9-kb & Haima et al., 1987 \\
pBT163 (pHP13-pac) & pHP13 derivative containing SPP1 DNA including pac (2675 bp cloned, coordinates 43778-44010 & Chai et al., 1992 \\
& and 1-2439) & Chai et al., 1993 \\
pBT271 (pHP13-oriL) & pHP13 derivative containing SPP1 DNA including oriL (2975 bp, coordinates 33875-36850) & This work \\
pBT400 (pHP13-800) & pHP13 derivative containing SPP1 DNA (864 bp, coordinates 3225-4089) & Leonhardt, 1990 \\
pUB110 & Natural RCR plasmid, 4.5-kb & Leonhardt, 1990 \\
pUB110-cop1 & pUB110 derivative, lower copy number & Deichellbohrer et al., 1985 \\
pBG55 (pUB110-3600) & pUB110 derivative containing SPP1 DNA (3639 bp, coordinates 23117-26756) & Ceglowski et al., 1993a \\
pBT233 & Theta replicating (TR) plasmid, 9-kb & This work \\
pBT233N & pBT233 derivative containing the 1304 bp neomycin resistance gene (N) from pUB110 & This work \\
pBT233N-400 & pBT233N derivative containing SPP1 DNA (414 bp, coordinates 32562-32976) & This work \\
pBT233N-1300 & pBT233N derivative containing SPP1 DNA (1340 bp, coordinates 25051-26391) & This work \\
pBT233N-oriL & pBT233N derivative containing SPP1 oriL DNA (350 bp, coordinates 35801-36151 & This work \\
pBT233N-pac & pBT233N derivative containing SPP1 pac DNA (412 bp, coordinates 43689-44010 and 1-70) & Titok et al., 2003 \\
pNDH33 & TR plasmid derivative of pBS72, 8.1-kb & This work \\
pNDH33-1300 & pNDH33 derivative containing SPP1 DNA (1340 bp, coordinates 25051-26391) & This work \\
pNDH33-pac & pNDH33 derivative containing SPP1 pac DNA (412 bp, coordinates 43689-44010 and 1-70) &
\end{tabular}

TABLE 2 | SPP1 phages used in this work.

\begin{tabular}{llll}
\hline Genotype & Name & Activity / type of mutant & Reference \\
\hline wt & SPP1wt & Wild type & This work \\
$34.1^{-}$ & sus34.1 & Exonuclease, ochre mutant (OM) & This work \\
$35^{-}$ & sus35 & Recombinase, OM & This work \\
$35^{-}$ & tsl2OF & Recombinase/thermosensitive (ts) mutant & This work \\
$36^{-}$ & sus36 & ssDNA binding protein, OM & Pedre et al., 1994 \\
$38^{-}$ & tsB3 & Replisome organizer/ts mutant & Pedre et al., 1994 \\
$39^{-}$ & sus53 & Helicase loader, OM & Pedre et al., 1994 \\
$40^{-}$ & sus109 & Helicase, OM & Zecchi et al., 2012 \\
$44^{-}$ & SPP1 $\Delta \mathrm{A}$ & Deletion mutant lacking Holliday junction resolvase & Chai et al., 1992 \\
$2^{-}$ & sus19 & Terminase large subunit, OM &
\end{tabular}


obtain the recombinant phages. They were picked from LuriaBertani (LB) plates supplemented with $10 \mathrm{mM} \mathrm{MgCl}_{2}$ (LB$\mathrm{Mg}^{+}$) incubated at $50^{\circ} \mathrm{C}$. The amplified phage was sequenced to confirm that phages had acquired the ochre mutation in gene 35, and that it had reverted to wt the tsI20F mutation. The resulting mutant phage, containing the ochre codon, was named SPP1 sus35.

The 37th codon (Lys) in gene 36 was replaced by an ochre (UAA) stop codon in a pHP13 derivative containing SPP1 genes 34.4 to 37 . The SPP1 sus34.1 mutant was generated by replacing, in a pHP13 derivative containing SPP1 genes 34.1 to 35 , the 31 th codon (AAA) of gene 34.1 by an ochre (UAA) stop codon. The SPP1 sus36 and sus34.1 mutants were then generated by homologous recombination between the SPP1 tsI20F phage and these plasmids carrying the stop ochre codon into the gene to be mutated, as described above. The accuracy of the resulting mutant phages was confirmed by sequencing.

SPP1wt, SPP1 $\triangle \mathrm{A}$ phages and the thermosensitive phages (tsI20F, and tsB3) were amplified in BG214 cells grown at $37^{\circ} \mathrm{C}$ or $30^{\circ} \mathrm{C}$ in $\mathrm{LB}-\mathrm{Mg}^{+}$, whereas the sus phages were routinely amplified in the suppressor strain BG295 (sup3) at $37^{\circ} \mathrm{C}$.

\section{Preparation of Transducing Lysates}

Transducing lysates were obtained by infecting with the different SPP1 phages, at a multiplicity of infection (MOI) of 10, B. subtilis BG214 cells bearing the indicated plasmids, grown up to midexponential phase in $\mathrm{LB}_{-} \mathrm{Mg}^{+}$and appropriated antibiotics. Aliquots were taken at different post-infection times for DNA analysis and processed as described below. The cultures were centrifuged after $90 \mathrm{~min}$ of infection $(14,000 \mathrm{rpm}, 5 \mathrm{~min})$, and the supernatants were filtered through $0.45 \mu \mathrm{m}$ filters to remove donor cells. Under these growth conditions B. subtilis cells are not competent, so that DNAse I treatment was not required. Phage lysates were titrated on BG214 cells or BG295 cells before use and were stored at $4^{\circ} \mathrm{C}$.

\section{Plasmid Transduction}

Exponentially growing recipient $B$. subtilis BG214 or BG295 cells $\left(\mathrm{OD}_{560}=0.4\right)$ grown at $37^{\circ} \mathrm{C}$ in $\mathrm{LB}-\mathrm{Mg}^{+}$, were infected with the transducing phage lysate at MOI of 1 . Phages were allowed to be absorbed for $5 \mathrm{~min}$, and then the non-absorbed phages were removed by centrifugation. Cell pellets were washed and finally resuspended in $1 \mathrm{ml} \mathrm{LB}$. Appropriate dilutions were plated in selective LB-agar plates containing the respective antibiotics, and incubated overnight at $37^{\circ} \mathrm{C}$ to quantify the number of transductants. As a control, $1 \mathrm{ml}$ of the recipient host was plated to discard the appearance of spontaneous resistant colonies. In another LB-agar plate with antibiotic the same amount of the stock transducing lysate was plated without recipient cells, to discard a contamination with donor cells.

\section{Analysis of Plasmid DNA Forms}

B. subtilis BG214 cells bearing the different plasmids were grown at $37^{\circ} \mathrm{C}$ to an $\mathrm{OD}_{560}$ of 0.40 in $\mathrm{LB}-\mathrm{Mg}^{+}$media supplemented with appropriate antibiotics, and infected with a MOI of 10 . Phage addition marked the time zero of our experiments. At given times, aliquots of $1 \mathrm{ml}$ were collected, rapidly placed in a water-ice mixture and centrifuged for $5 \mathrm{~min}$ at $14,000 \mathrm{rpm}$ and $4^{\circ} \mathrm{C}$. The pellets were stored at $-80^{\circ} \mathrm{C}$. In experiments with thermosensitive phage mutants, the strains bearing plasmids were first grown at $30^{\circ} \mathrm{C}$ to an $\mathrm{OD}_{560}$ of 0.2 , transferred to $50^{\circ} \mathrm{C}$ and then further grown to $\mathrm{OD}_{560}$ of 0.4 . They were infected at $50^{\circ} \mathrm{C}$, and the samples were processed as described above. Total DNA was isolated following a protocol described earlier (Viret and Alonso, 1987) with some minor modifications. Samples were resuspended in $200 \mu \mathrm{l}$ of lysis buffer $(25 \mathrm{mM}$ Tris- $\mathrm{HCl}$ pH 8.0, 50mM glucose, $10 \mathrm{mM}$ EDTA, $0.5 \mathrm{mg} / \mathrm{ml}$ lysozyme and $0.1 \mathrm{mg} / \mathrm{ml} \mathrm{RNase} \mathrm{A).} \mathrm{After} 30 \mathrm{~min}$ of incubation at $30^{\circ} \mathrm{C}$, Proteinase $\mathrm{K}(0.5 \mathrm{mg} / \mathrm{ml})$ and SDS $(0.8 \%)$ were added, and the mixture was further incubated for $30 \mathrm{~min}$ at $37^{\circ} \mathrm{C}$. The lysate obtained was then treated twice with phenol and dialyzed against $20 \mathrm{mM}$ Tris- $\mathrm{HCl} \mathrm{pH}$ 8.0, 1 mM EDTA.

Pulsed field gel electrophoresis (PFGE) was performed on a Bio-Rad CHEF-DR II apparatus. $15 \mu \mathrm{l}$ of samples were loaded on the $1 \%$ agarose gel. Running conditions were $5 \mathrm{~V} / \mathrm{cm}, 0.5 \%$ TBE, $0.5-10$ switch time for $20 \mathrm{~h}$ at $14^{\circ} \mathrm{C}$. The molecular weight marker used was LW range PFG marker or $\lambda$ DNA-HindIII digest, both from New England Biolabs. The probe used for Southern blot hybridization was a PCR product of $500 \mathrm{bp}$ corresponding to neomycin or chloramphenicol resistance genes. Southern blots were performed with Hybond-N+ membranes as recommended by the manufacturer (GE Healthcare), and detection was done with the AlkPhos Direct Labeling kit (GE Healthcare).

\section{RESULTS}

\section{Viral Replication and Recombination Proteins Are Responsible for the Generation of Plasmid Transducing Particles}

To unravel the mechanisms that contribute to SPP1-mediated horizontal plasmid transfer we used B. subtilis BG214 strain, which is non-inducible for PBSX prophage and lacks prophage $\mathrm{SP} \beta$ and the ICEBs 1 integrative conjugative element. To analyze the role in antibiotic resistance transfer of SPP1 replication and recombination proteins, phages sus34.1 and sus36, bearing mutations in genes 34.1 and 36 respectively, were constructed. SPP1 phage variants bearing mutations in the other genes were available in our phage collection (sus19, sus53, sus109, $\mathrm{SPP} 1 \triangle \mathrm{A}$, tsB3). For comparison, a SPP1 sus35 phage was also constructed, although a thermosensitive gene 35 mutant (the tsI20F phage) was available. The list of the bacteriophages used is shown in Table 2.

First we analyzed if G34.1P and G36P proteins, which were not yet studied in vivo, are essential for SPP1 replication (Figure 1). BG214 cells were grown until mid-exponential phase and then infected at MOI of 10 with the SPP1wt, SPP1 $\triangle \mathrm{A}$, tsB3 (at restrictive temperature), or the different sus mutants (sus34.1, sus35, sus36, and sus53, a phage with a mutation in gene 39). After 90 min of infection, the phage lysates were collected and titrated. As previously observed, deletion of gene 44 reduced the 


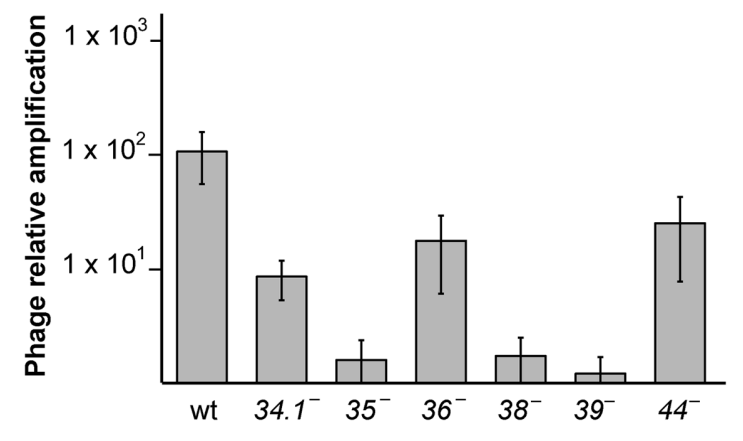

FIGURE 1 | Effect of the different SPP1 mutations on phage titer. B. subtilis BG214 cells were infected with the different phages at a MOI of 10 , and after $2 \mathrm{~h}$ of infection PFU/ml was calculated. The number of phages, relative to the number of phages initially added, is indicated. The values are the mean of at least five independent assays and error bars indicate SD.

phage titer only 5 -fold (Zecchi et al., 2012), whereas the mutation in gene 35,38 or 39 completely abolished SPP1 amplification (Pedre et al., 1994; Ayora et al., 2002). The mutation in gene 36 reduced SPP1 titer only 6 -fold, in agreement with the biochemical data showing that G36P can be replaced by the host SsbA during SPP1 DNA replication (Seco et al., 2013; Seco and Ayora, 2017). Deletion of the 34.1 gene reduced the phage titer 10 -fold, and the size of the phage plaques was considerably smaller compared to the wt phage (Supplementary Figure S1). These results show that both, G36P, and G34.1P are not essential for phage amplification, although their defects reduce phage development.

To analyze if SPP1 replication and recombination proteins are involved in the generation of the transducing particle, the different sus mutant phages were used to infect BG214 cells bearing plasmid pBG55, a rolling circle replicating (RCR) plasmid with high-frequency of transduction (see Table 1 for more description). The lysates were collected after $90 \mathrm{~min}$ of infection, filtered and used to infect the BG295 sup3 strain, to have the effect of phage sus mutation only in the donor and not in the recipient strain. The frequency of pBG55 transfer (Neomycin resistants $\left[\mathrm{Nm}^{\mathrm{R}}\right] / \mathrm{CFU}$ ) for the wt phage was similar to previously published results obtained using the BG214 strain, both as donor and as recipient (Deichelbohrer et al., 1985). These results show that the sup3 genotype does not affect the transduction frequency. In parallel, infections with the thermosensitive phage mutants were performed at $50^{\circ} \mathrm{C}$ for $90 \mathrm{~min}$. The lysates were then collected, filtered and used to infect BG214 cells at $30^{\circ} \mathrm{C}$ to have the effect of the thermosensitive mutation only in the donor, and not in the recipient strain. Mutations in genes 35, 38, or 39 blocked the transfer of the plasmid with homology (pBG55), with more than 1000-fold reduction in the transduction frequency (Figure 2A). A similar result was obtained with sus109, bearing a mutation in gene 40 (data not shown). Mutations in the exonuclease (G34.1P) or in the viral SSB (G36P) reduced the transduction frequency by $\sim 12$-fold, whereas the mutation in G44P only reduced it by $\sim 4$-fold.

To analyze if these proteins are also involved in the transfer of plasmids having no homology with the SPP1 phage, or

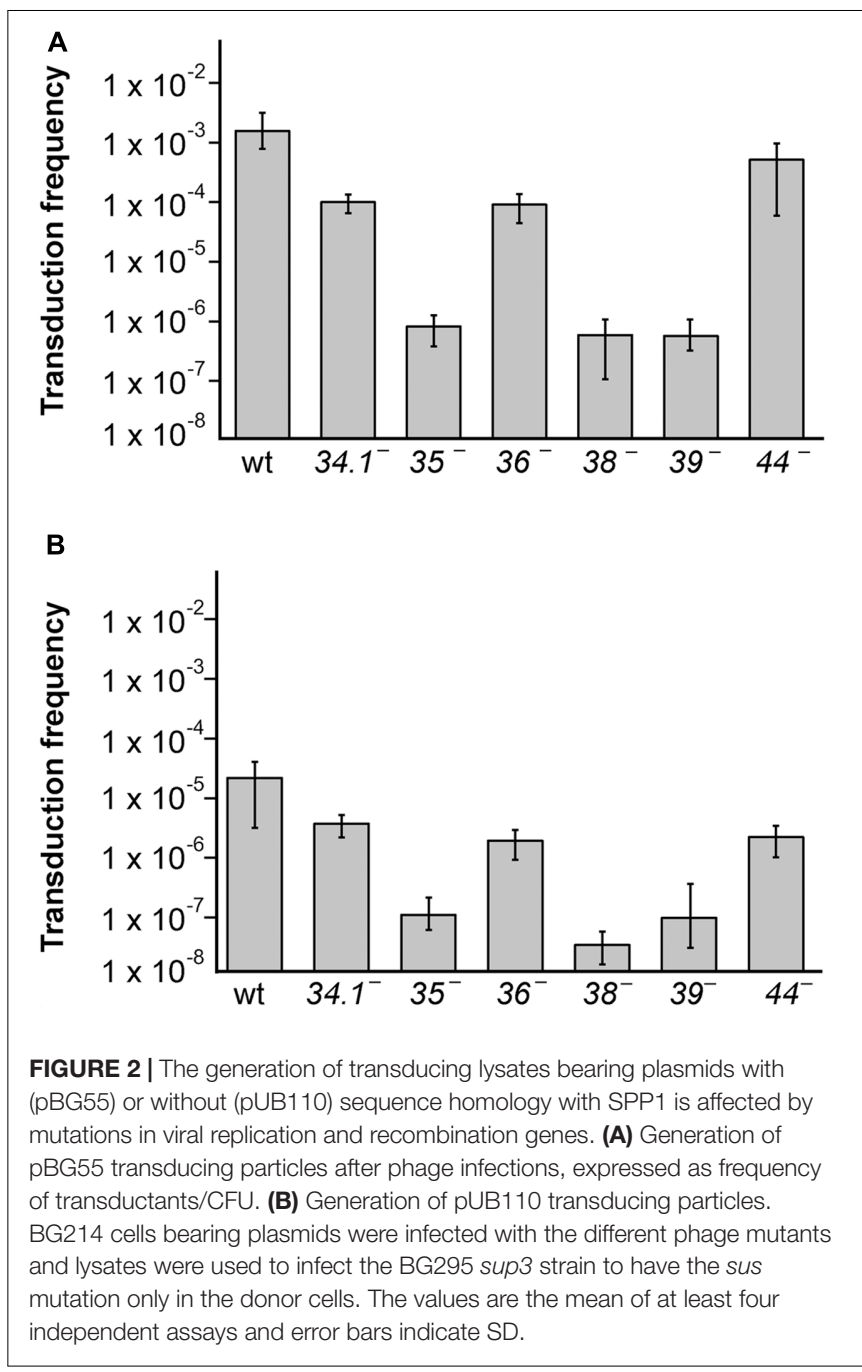

just very short homologous regions (sequences of 11-16 bp complementary to SPP1 DNA, see Supplementary Table S1) we performed transduction assays with the natural occurring pUB110 plasmid and the different phage mutants (Figure 2B). As already observed the transduction frequency of this plasmid was reduced by a factor of $\sim 100$-fold compared to the frequency of pBG55 transduction. The transduction frequencies were reduced in all of the SPP1 mutants, and similarly to the results obtained with the plasmid having homology, mutations in the recombinase or in replication proteins drastically reduced the phage-mediated transfer of pUB110, whereas mutations in the exonuclease, the $\mathrm{SSB}$, or the HJ resolvase reduced the number of transductants $/ \mathrm{ml}$ to a lesser extent.

\section{SPP1 Replication and Recombination Proteins Are Essential for the Generation of Plasmid Concatemeric DNA}

Concatemeric plasmid DNA synthesis was observed with RCR plasmids after phage infection (Alonso et al., 1986; Bravo and Alonso, 1990). The results obtained in the previous section 

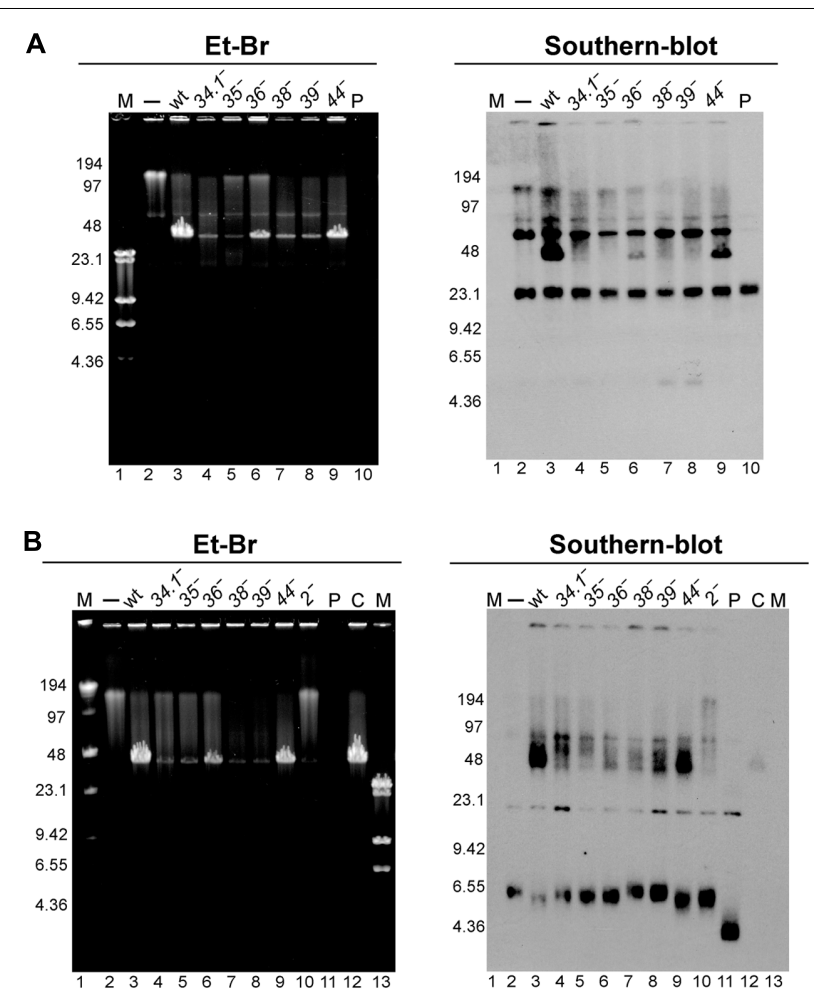

FIGURE 3 | Analysis of the appearance of the transducing particles after infection with different SPP1 mutants of cells bearing RCR replicating plasmids with (pBG55 infections, A) or without regions homologous to SPP1 DNA (pUB110 infections, B). To unravel the appearance of $h m w$ plasmid DNA 30 min after phage infections samples were analyzed by PFGE and $\mathrm{Et}-\mathrm{Br}$ staining (left panel) followed by Southern-blot (right panel). M, LW and $\lambda$-Hindlll markers. P, purified plasmid DNA 15 ng (pBG55 in A, and pUB110 in B); C, control, a SPP1 infection of BG214 cells without plasmid.

suggest that the essential viral recombination (G35P) and replication (G38P, G39P, and G40P) proteins could be responsible for the generation of this linear concatemeric plasmid DNA. To test this, we infected BG214 cells bearing pBG55 with the different phage mutants. After $30 \mathrm{~min}$ of infection, the infected cells were collected, total DNA was extracted, and separated by PFGE and Southern blotted to detect the production of concatemeric plasmid DNA forms. After infection with the wt phage the appearance of plasmid DNA that migrates with the bulk of SPP1 DNA (i.e., a multimeric plasmid DNA band of 44-kb) was observed (Figure 3A). In the absence of G35P, G38P or G39P, the production of this concatemeric band was not observed, consistent with the above result that mutations in these proteins block plasmid transduction. In agreement with its minor role in plasmid transfer, the 44 -kb plasmid DNA band was observed after infection with phages bearing mutations in G34.1P, G36P, or in G44P. Moreover, the amount of 44-kb pBG55 DNA observed by PFGE and Southern blot correlated in these mutants with their transduction frequencies.

We also observed the appearance of a similar 44-kb plasmid band after infection with the wt SPP1 phage of cells bearing the natural pUB110 plasmid (Figure 3B). In concordance with observations using the plasmid with extensive homology, the appearance of this 44-kb plasmid DNA band was clearly observed after infections with SPP1wt and SPP1 $\triangle \mathrm{A}$ phages, which showed the highest transduction frequencies.

\section{Viral Replication and Recombination Proteins Are Not Involved in the Establishment of the Transduced Plasmid}

The results presented above and in earlier reports (Deichelbohrer et al., 1985; Bravo and Alonso, 1990) indicate that a concatemeric $\sim 44$-kb plasmid DNA is encapsidated into the viral capsids. Once this concatemeric plasmid DNA (5.4 plasmid copies in the case of pBG55 plasmid) is injected into a recipient cell, it needs to circularize and monomerize to prepare the plasmid for correct replication and segregation cycles. The duplicated regions present in the concatemer could be used for monomerization, through a homologous recombination event, as it occurs during natural plasmid transformation (Kidane et al., 2009). In order to analyze if the viral replication and recombination machinery is involved in this monomerization and plasmid establishment process, we performed transduction assays with sup3 as donor and wt as recipient cells (Table 3). It appeared that none of the viral proteins were required for the establishment of the transduced plasmid in the recipient cells.

\section{The Influence of Plasmid Copy Number and Replication Mode in Transduction}

Plasmid-borne genes are transduced at much higher frequency than chromosomal-borne genes (Ferrari et al., 1978; Deichelbohrer et al., 1985), suggesting that copy number of plasmids could account for such differences. However, there is no tight correlation. As an example, it was published that the transduction frequency of plasmid pUB110, which has $\sim 50$ copies per cell (Viret and Alonso, 1988) is lower than that of pC1943 with $\sim 15$ copies per cell (Deichelbohrer et al., 1985). We confirmed these results (Table 4). This suggests that plasmid copy number is not the major determining factor, or not the only one. Other factors such as the presence of pseudo-pac sites, or of single-stranded (ssDNA) plasmid forms (recombinogenic particles, see below) could be the cause of this increased transduction frequency. Both plasmids, pUB110 and pC194, are RCR plasmids, but it was found that pC194 is more prone to formation of ssDNA than pUB110 (te Riele et al., 1986; Viret and Alonso, 1987).

To elucidate the influence of copy number, we compared the transduction efficiency of plasmid pUB110 (48 \pm 4 copies/cell) and its derivative pUB110-cop1 ( $9 \pm 1$ copies/cell). pUB110cop1 results from a single mutation in pUB110 plasmid, and therefore it has the same amount of ssDNA as the parental plasmid, but its copy number is reduced by 5 -fold (Leonhardt, 1990). Both plasmids should have similar rates of circularization and establishment when they are injected into the recipient cell. As shown in Table 4, the transduction efficiency of pUB110-cop1 was proportionally reduced 4.6 times. In parallel we compared also the transduction frequencies of two other plasmids that 
accumulate ssDNA, pC194 (15 \pm 2 copies per cell, Alonso and Trautner, 1985) and pHP13 (a pTA1060 derivative, $7 \pm 2$ copies per cell, Wang et al., 2004). Here also the transduction efficiency decreased by lowering the copy number of the plasmids. Nevertheless in all cases the transduction frequencies were higher for the plasmids accumulating ssDNA intermediates (Table 4).

Previous studies of the plasmid transduction by the SPP1 phage were done only with RCR plasmids. To determine the transduction frequency of theta replicating (TR) plasmids we used two such plasmids: pBT233 and pNDH33, which have a copy number similar to that of pHP13 plasmid (Table 1). Plasmid pBT233 is a pSM19035 derivative (erythromycin resistant), which has a copy number of $\sim 8 \pm 2$, and replicates unidirectionally by a DNA polymerase I (PolI)-dependent theta mechanism (Ceglowski et al., 1993a,b,c). Plasmid pNDH33 is a derivative of pBS72 (chloramphenicol resistant) with a copy number of $\sim 6 \pm 1$ plasmids/cell (Nguyen et al., 2005; Phan et al., 2006). pNDH33 is thought to replicate by a DnaA-dependent and DNA PolI-independent theta type mechanism (Titok et al., 2003; Schumann, 2007). To compare TR and RCR plasmids, and to eliminate any resistance marker effects, the neomycin gene of the pUB110 was cloned into plasmid pBT233, to render plasmid pBT233N. The transduction frequency of the TR plasmid pBT233N was about 70-fold lower than that of pHP13. We measured also the transduction frequency of the second TR plasmid, pNDH33. This appeared to be also low, but only $\sim 10$-fold lower than that of pHP13 plasmid (Table 4). This higher transduction could be due to the occasional presence in the pNDH33 plasmid of a pseudo-pac site or because of a 16 bp stretch of homology (Table 4 and Supplementary Table S1). When analyzing the fate of TR plasmids in infected cells, it was observed that, as with RCR plasmids, the infection with wt SPP1 phage produced the accumulation of a $44-\mathrm{kb}$ plasmid DNA band, which was not observed after infection with a sus 35 mutant (Figure 4).

\section{The Presence of Homology to Phage Enhances the Transduction of TR Plasmids}

When the phage packaging signal ( $p a c$ ) was integrated into the host chromosome, SPP1 mediated the transduction of chromosomal genes located close to the region of integration of the pac signal (Bravo et al., 1990). It was not tested if the presence of other SPP1 regions also increases the transduction frequencies of chromosomal DNA. To test this, we used the pBT233N derivative conferring $\mathrm{Nm}^{\mathrm{R}}$, which replicates via the theta-type mechanism as the chromosome. Different regions of SPP1 were cloned into $\mathrm{pBT} 233 \mathrm{~N}$ in order to evaluate whether the presence of pac sequence or the replication origin (oriL) results in higher transduction than simply homology to the phage (Table 5). Overall, the presence of a homologous region increased the transduction frequency of pBT233N plasmid by more than 1000-fold, and this increase was observed independently of the homologous region cloned (pac, oriL, or a 400 bp or $1000 \mathrm{bp}$ region unrelated to replication and packaging processes).

TABLE 3 | Viral replication and recombination proteins are not involved in the establishment of transduced plasmids.

\begin{tabular}{|c|c|c|c|c|c|}
\hline Donor strain ${ }^{a}$ and plasmid & Recipient strain & Phage & Transduction Frequency & $S D^{c}$ & $\mathrm{TF}^{\mathrm{M}} / \mathrm{TF}^{\mathrm{wt}}$ \\
\hline BG295 pBG55 & BG214 & SPP1 wt & $4.3 \times 10^{-3}$ & $\pm 2.0 \times 10^{-3}$ & $1.00^{d}$ \\
\hline BG295 pBG55 & BG214 & $34.1^{-}$ & $3.4 \times 10^{-3}$ & $\pm 1.5 \times 10^{-3}$ & $7.9 \times 10^{-1}$ \\
\hline BG295 pBG55 & BG214 & $35^{-}$ & $2.1 \times 10^{-3}$ & $\pm 1.1 \times 10^{-3}$ & $4.9 \times 10^{-1}$ \\
\hline BG295 pBG55 & BG214 & $36^{-}$ & $3.4 \times 10^{-3}$ & $\pm 1.8 \times 10^{-3}$ & $7.9 \times 10^{-1}$ \\
\hline BG214 pBG55e & BG214 & $38^{-}$ & $4.3 \times 10^{-3}$ & $\pm 2.1 \times 10^{-3}$ & $1.0 \times 10^{0}$ \\
\hline BG295 pBG55 & BG214 & $39^{-}$ & $2.9 \times 10^{-3}$ & $\pm 2.0 \times 10^{-3}$ & $6.7 \times 10^{-1}$ \\
\hline
\end{tabular}

${ }^{a} B G 214$ is the wild type strain and BG295 is the isogenic sup3 strain. ${ }^{b}$ The transduction frequency (Neo $\left.{ }^{R} / C F U\right)$ is the average of at least three independent experiments.

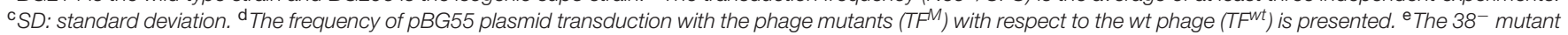

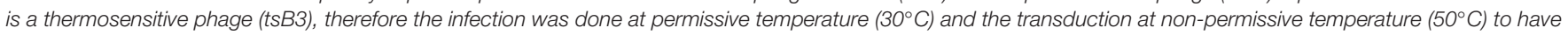
the mutation only in the recipient strain.

TABLE 4 | Transduction frequency of theta and rolling circle replicating plasmids without sequence homology with SPP1.

\begin{tabular}{|c|c|c|c|c|c|c|c|}
\hline Plasmid & $\begin{array}{c}\mathbf{A b}^{\mathbf{R}} \\
\text { marker }\end{array}$ & $\begin{array}{l}\text { Replication } \\
\text { mechanism }^{a}\end{array}$ & $\begin{array}{c}\text { Copy } \\
\text { number }^{b}\end{array}$ & $\begin{array}{c}\text { ssDNA } \\
\text { production }^{c}\end{array}$ & pseudo-pac site ${ }^{\mathrm{d}}$ & $\begin{array}{l}\text { Transduction } \\
\text { Frequencye }^{\mathrm{e}}\end{array}$ & $\mathrm{Cl}_{0.95}{ }^{\mathrm{f}}$ \\
\hline pUB110 & $\mathrm{Nm}$ & $\mathrm{RCR}$ & 50 & + & - & $2.1 \times 10^{-5}$ & $\pm 1.3 \times 10^{-5}$ \\
\hline pUB110-cop1 & $\mathrm{Nm}$ & $\mathrm{RCR}$ & 15 & + & - & $4.3 \times 10^{-6}$ & $\pm 2.2 \times 10^{-6}$ \\
\hline pC194 & $\mathrm{Cm}$ & $\mathrm{RCR}$ & 15 & +++ & - & $5.2 \times 10^{-5}$ & $\pm 4.7 \times 10^{-5}$ \\
\hline pHP13 & $\mathrm{Cm}$ & $\mathrm{RCR}$ & 5 & +++ & - & $5.9 \times 10^{-6}$ & $\pm 2.9 \times 10^{-6}$ \\
\hline pBT233N & $\mathrm{Nm}$ & TR & 8 & - & - & $8.2 \times 10^{-8}$ & $\pm 7.1 \times 10^{-8}$ \\
\hline pNDH33 & $\mathrm{Cm}$ & TR & 6 & - & 1 & $6.4 \times 10^{-7}$ & $\pm 3.2 \times 10^{-7}$ \\
\hline
\end{tabular}

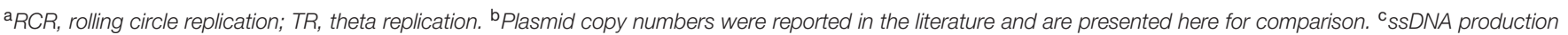

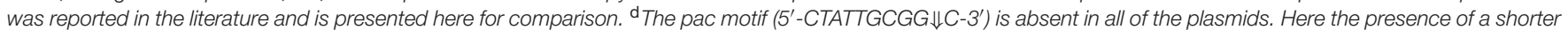
motif that we call pseudo-pac site $5^{\prime}-T$ TGCGG $\downarrow C W-3^{\prime}$ is indicated. ${ }^{\circ}$ The transduction frequency (transductans/CFU) is the mean of at least five independent experiments. ${ }^{\mathrm{f}} \mathrm{Cl}$, confidence interval. 
Similarly, cloning into a RCR plasmid ( $\mathrm{pHP13}$ ) one of the phage origins of replication of SPP1 did not further increase the transduction frequency (Supplementary Table S2). Using of other TR-type replicon, pNDH33, provided similar results (Table 5). Furthermore, the accumulation of the $44-\mathrm{kb}$ plasmid band was higher in the TR plasmids derivatives having homology with the phage (Figure 4, and data not shown).

\section{DISCUSSION}

Until recently, it was thought that generalized transduction occurred at low frequency. However, recent single-cell analyses observed transduction rates close to $1 \%$ per plaque forming units when natural communities were used as recipients (Kenzaka et al., 2010). Therefore the study of the transduction mechanisms is essential to prevent this highly frequent horizontal gene transfer process, to avoid the spread of antibiotic resistance among bacteria. In this aspect, the SPP1 bacteriophage is a valuable model, because its replication, recombination, and packaging machineries haven been studied in deep for many years. Furthermore, it was recently reported that SPP1 can occasionally infect resistant cells when combined with sensitive cells, providing new routes for horizontal gene transfer (Tzipilevich et al., 2017). Previous biochemical studies assigned a role to SPP1 proteins G34.1P, G35P, G36P, G38P, G39P, G40P, and $\mathrm{G} 44 \mathrm{P}$ in replication and recombination, but their contribution to generalized plasmid transduction remained unknown. Here we show that all SPP1 replication proteins contribute to horizontal plasmid transfer, although to a different extent. The origin binding protein (G38P), helicase loader (G39P), and helicase (G40P) are essential to produce concatemeric plasmid DNA, which is synthesized after phage infection. Infections with the sus 36 mutants show only a 10 -fold reduction in the transduction frequency, probably due to potential complementation of the G36P function by cellular SsbA protein (Seco et al., 2013; Seco and Ayora, 2017). The SPP1 recombination proteins contribute to plasmid transfer to a different extent. The exonuclease G34.1P and the Holliday junction resolvase G44P only contribute partially to plasmid transduction, with a reduction of the

TABLE 5 | Transduction frequency of theta replicating plasmids bearing different SPP1 DNA regions.

\begin{tabular}{|c|c|c|c|c|}
\hline Plasmid & Length of homologous region & Special features & Transduction Frequency ${ }^{a}$ & $\mathrm{Cl}_{0.95^{\mathrm{b}}}$ \\
\hline pBT233N-400 & $414 \mathrm{bp}$ & homology & $3.1 \times 10^{-5}$ & $\pm 1.9 \times 10^{-5}$ \\
\hline pBT233N-pac & $412 \mathrm{bp}$ & pac & $1.7 \times 10^{-4}$ & $\pm 2.8 \times 10^{-4}$ \\
\hline pBT233N-oriL & $360 \mathrm{bp}$ & oriL & $1.5 \times 10^{-4}$ & $\pm 1.6 \times 10^{-4}$ \\
\hline pNDH33 & - & - & $5.6 \times 10^{-7}$ & $\pm 2.9 \times 10^{-7}$ \\
\hline pNDH33-pac & $412 \mathrm{bp}$ & pac & $3.9 \times 10^{-4}$ & $\pm 3.2 \times 10^{-4}$ \\
\hline
\end{tabular}

${ }^{\mathrm{a}}$ The transduction frequency (transductans/CFU) is the mean of at least five independent experiments. ${ }^{\mathrm{b}} \mathrm{Cl}$, confidence interval.

A

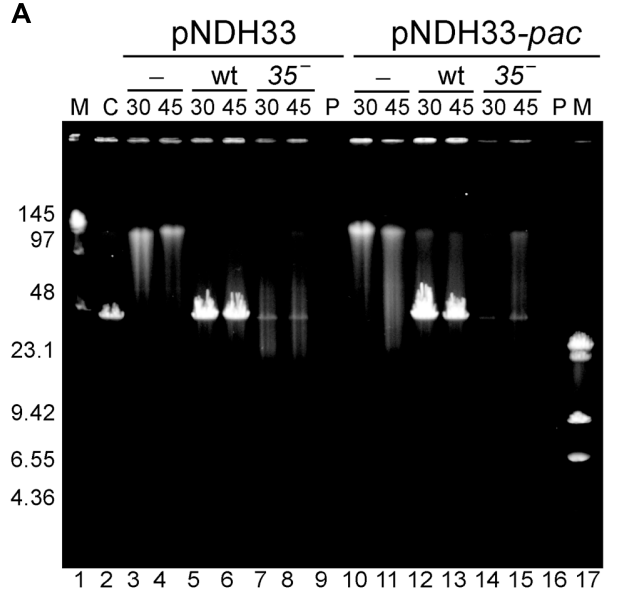

B

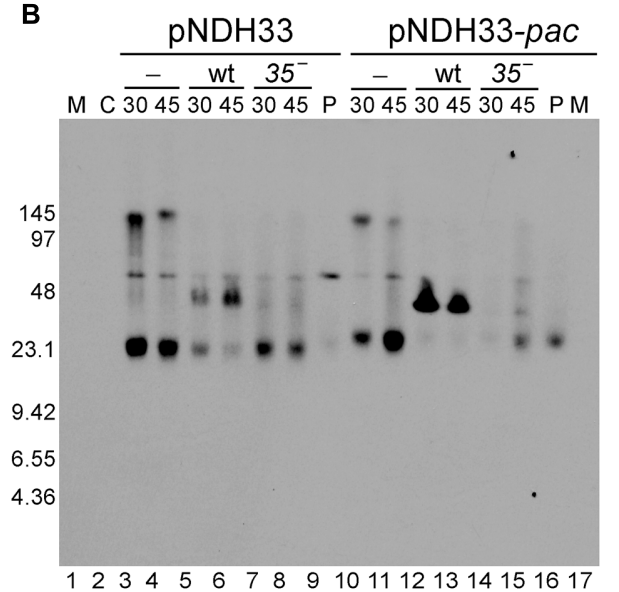

FIGURE 4 | Southern-blot analysis of the appearance of the transducing particles after infection with SPP1 or with sus 35 phage of cells bearing TR plasmids having (pNHD33-pac) or lacking (pNDH33) homologous regions to the phage. (A) Ethidium bromide stain and (B) Southern blot of the same gel developed with a chloramphenicol probe to visualize plasmid DNA. Lanes: 1 and 17: LW and $\lambda$-Hindlll markers. Lane 2: C, control SPP1 infection of BG214 cells without plasmid. Lanes 3-4 and 10-11: control, non-infected BG214 cells bearing pNDH33 or pNDH33-pac plasmid. Lanes 5-6 and 12-13: SPP1 infection of BG214 cells bearing pNDH33 or pNDH33-pac plasmid, after 30 and 45 min infection. Lanes 7-8 and 14-15: BG214 cells bearing pNDH33 or pNDH33-pac, after 30 and 45 min infection with sus35 phage. Lane 9 and lane 16: P, 15 ng of purified pNDH33 or pNDH33-pac respectively. 
transduction frequency of 12- and 5-fold in their mutants, respectively. The G35P recombinase is essential, with its inactivation leading to a $>100$-fold decrease.

Previous studies with SPP1 and RCR plasmids showed that: (i) the transduction of pUB110 and pC194 plasmids was enhanced 100 - to 1000-fold when there was any homology between the plasmid and the SPP1 genome rather than with the specific pac signal; (ii) pUB110 and pC194 plasmid transduction was independent on RecA (Deichelbohrer et al., 1985), and (iii) linear plasmid concatemeric DNA (or high-molecular-weight [hmw] DNA) accumulated during phage infection, and in certain genetic backgrounds (Viret and Alonso, 1987; Viret et al., 1991). The synthesis of $h m w$ DNA and its independence of the host-encoded recombinase (RecA) strongly suggests that the formation of transducing particles may rely on viral replication and/or recombination functions. In this work we show that the synthesis of this $h m w$ DNA, and consequently transduction of RCR plasmids requires an active G35P protein. Biochemical analysis shows that G35P is an ATP-independent single-strand annealing enzyme, similar to the RecT enzyme encoded by the Rac prophage (Ayora et al., 2002). Both, G35P and RecT, belong to the $\operatorname{Red} \beta$ family of viral single strand annealing proteins. To date, five different single strand annealing recombinase families have been identified in phages: Sak, Red $\beta, \operatorname{Erf}$, Sak4 and Gp2.5 (Lopes et al., 2010). These recombinases have gained increased attention in recent years because of their abundance in phage genomes (Lopes et al., 2010; Delattre et al., 2016), and also due to their wide use in recombineering systems (Datta et al., 2008; Sun et al., 2015). Many of these recombinases, including G35P, are essential for the phage life cycle (Zecchi et al., 2012; Neamah et al., 2017).

In this work we found that variations in copy-number affect the transduction frequency. Since the transduction is a stochastic process, it is expected that the more plasmid DNA in the cell the more generalized transducing phage particles should carry a plasmid copy and therefore the chances of transduction increase. The plasmids replicating in B. subtilis cells are either of the TR (circle-to-circle) type or RCR (sigma) type, and the products of both replication modes are usually covalently closed circular monomers (Khan, 2005). Comparing plasmids with similar copy number we observed that the frequency of transduction for RCR plasmids is $\sim 60$-fold higher than that for TR plasmids. This result suggests that the type of DNA replication also determines the transduction frequency. In the small RCR plasmids leading and lagging strand replication are uncoupled, and they contain two modules: the Rep protein with its cognate double-strand origin (DSO), and a single strand origin (SSO), which functions as the major initiation site for lagging-strand synthesis (Alonso et al., 1988; Espinosa et al., 1995; Khan, 2005). All RCR plasmids accumulate ssDNA although to a different extent: pUB110 accumulates traces and pC194 accumulates circular ssDNA (te Riele et al., 1986; Viret and Alonso, 1988). In contrast, the large low-copy-number TR plasmids, such as pBT233, which replicates via an unidirectional mechanism, do not accumulate circular ssDNA intermediates (Ceglowski et al., 1993b,c). We propose that the high transfer frequencies of some RCR plasmids may be correlated with the high accumulation of recombinogenic ssDNA intermediates in these plasmids. Such ssDNA intermediates may constitute the substrates for formation of the transducing particles, through a recombination catalyzed by the G35P protein. This is in agreement with recent results observed with viral recombinases: when analyzing their recombineering activity in vivo, it was found that they catalyze single-strand annealing preferentially on the lagging strand (van Kessel and Hatfull, 2008; Mosberg et al., 2010; Lajoie et al., 2012; Fricker and Peters, 2014; Ander et al., 2015). We propose that all the phages encoding recombinases will transduce RCR plasmids with high efficiency by the mechanism of viral recombinase-mediated generalized transduction. Furthermore, we also observed that the transduction of the pUB110 and pNDH33 plasmids, which do not have an extensive region of homology, was strongly reduced in infections with the sus35 mutant (Figures 2, 4). All phage recombinases studied so far are single-strand annealing proteins that promote genetic recombination under more permissive conditions than RecA (Scaltriti et al., 2011; De Paepe et al., 2014; Menouni et al., 2015). Our results suggest that G35P contributes to the transfer of natural plasmids by catalyzing a recombination reaction using small stretches of homology found in many plasmids (Supplementary Table S1).

The different contributions of the SPP1 recombination proteins to plasmid transduction, together with the high recombinogenic nature of the RCR plasmids, suggest that the initial DNA substrate, used for the production of transducing particles by recombination, is indeed ssDNA. This is consistent with the result that the G34.1P exonuclease, which resects the dsDNA ends to generate the appropriate substrate for the recombinase (Martinez-Jimenez et al., 2005), has a minor role in plasmid transfer. Similarly, we found that the SPP1 SSB protein, G36P, only slightly contributes to the mechanisms of plasmid transduction. However, in some phages the recombinases require the activity of their cognate SSB proteins to perform their function (Neamah et al., 2017).

It was previously observed with RCR plasmids that any SPP1 DNA segment larger than $50 \mathrm{bp}$, cloned into such plasmids, greatly increased the transduction frequency (Deichelbohrer et al., 1985; Alonso et al., 1986). We extend this observation to TR plasmids, where the transduction frequency was highly increased, independently of what is the region of homology cloned, whether it was the packaging sequence, a phage origin of replication, or any other region of homology. Similarly, the cloning of the origin of replication of SPP1 (oriL) into a RCR-type plasmid did not further increase its transduction frequency (Supplementary Table S2). We conclude that any DNA region homologous to the phage genome increases the frequency of horizontal transfer of plasmids, independently of their replication mechanism. Enhanced transduction of plasmids bearing homology with phage DNA has been also observed with phage T4, which codes for a different recombinase, the UvsX protein (Kreuzer et al., 1988), and with Salmonella typhimurium phage P22, which codes for the Erf recombinase (Orbach and Jackson, 1982).

How is the plasmid substrate for generalized transduction generated? Three different mechanisms could account for the generation of a concatemeric plasmid DNA with high frequency 
of transduction. In the first model, the multiple tandem repeats of plasmid DNA might be produced by intermolecular recombination, as proposed for P22 plasmid transduction (Mann and Slauch, 1997). This mechanism resembles phage T4 generation of concatemeric DNA during its replication (Kreuzer, 2000; Mosig et al., 2001). Here, multiple strand invasions catalyzed by the ATP-dependent RecA-like recombinase encoded by this phage, UvsX, and the resolution of the Holliday junction intermediates by its Holliday junction resolvase Gp49 (also called EndoVII), produce the concatemeric DNA, as well as the transducing particle (Kreuzer et al., 1988; Kreuzer, 2000; Mosig et al., 2001). We do not favor this hypothesis in the SPP1 system, because we found that the Holliday junction resolvase G44P has only a minor role in plasmid pBG55 and pUB110 transduction. In the second model, plasmid overreplication leads to the accumulation of linear concatemeric hmw DNA (Cohen and Clark, 1986; Viret and Alonso, 1987; Viret et al., 1991). The accumulation of linear head-to-tail multigenome-length plasmid DNA ( $h m w$ DNA) in the absence of RecBCD/AddAB was documented in both Escherichia coli and B. subtilis cells (Silberstein and Cohen, 1987; Viret and Alonso, 1987). Indeed, upon infection, many bacteriophages directly or indirectly inactivate end-resection catalyzed by this host encoded multi-subunit helicase-nuclease enzyme (Szczepanska, 2009). It was observed that the synthesis of pC194 or pUB110 $h m w$ plasmid DNA occurred in the absence of plasmidencoded Rep protein, and required DNA PolI, RecA and preprimosomal proteins (e.g., DnaB) (Viret and Alonso, 1987; Leonhardt et al., 1991; Viret et al., 1991). Analysis of this $h m w$ plasmid DNA by electron microscopy displayed linear DNA molecules up to $100 \mathrm{~kb}$ in size, which were either singlestranded, double-stranded or duplex DNA with single-stranded tailed ends (Leonhardt et al., 1991). This hmw DNA can be encapsidated into a viral prohead by a headful packaging mechanism (Schmidt and Schmieger, 1984; Schmieger, 1984). If this model is correct, the presence of a pac signal will significantly increase the encapsidation of the plasmid hmw DNA, and we found that there was not an increase in the transduction frequency when plasmids contained the pac signal. In the third model, phage infection arrests host and plasmid replication. Then SPP1-dependent replication restarts, and the linear plasmid concatemer is synthesized. This is consistent with the result that the phage G38P protein may act as a PriA-like enzyme, restarting DNA replication outside form a replication origin (Seco et al., 2013; Seco and Ayora, 2017). In this de novo synthesis of plasmid DNA, a viral pac site might be gained by recombination and recognized by the viral packaging machinery (Alonso et al., 1986; Bravo et al., 1990; Viret et al., 1991). In this model, the phage might form a phageplasmid chimera and the plasmid hijacks the viral replication machinery to promote de novo synthesis of linear plasmid concatemeric DNA. The concatemeric plasmid DNA is then packaged into an empty prohead by the headful mechanism, indistinguishable of viral DNA, provided that the packaged substrate is larger than mature phage DNA. Our data support the third model, because we found that in infections with a phage bearing a mutation in the terminase (sus19 infections), plasmid concatemers up to $200-\mathrm{kb}$ long are produced after phage infection (Figure 3B and Supplementary Figure S2). This model explains also the requirement of viral replication proteins for the formation of the transducing particles. However, we were unable to detect the phage-plasmid chimeras, which might be rapidly processed to produce the plasmid head-to-tail concatemers.

Our results show that the establishment of the transduced concatemeric plasmid in the host is independent of phage encoded recombination functions, which only participate in the generation of the transducing particle. We propose that the injected linear concatemer can be converted into a circular form by the homologous recombination machinery of the recipient cells. In this respect, transduction of plasmids might have similar host requirements as the resolution of phageplasmid chimeras analyzed in the P22 and SPP1 systems (Orbach and Jackson, 1982; Alonso et al., 1992). In the former case, the plasmid integrated into the phage genome has to be excised from the genome of the defective phage prior to establishment, whereas in the latter case the head-to-tail plasmid concatemer has to recombine intramolecularly to facilitate plasmid establishment. This process was found to be RecAindependent but dependent on host $\mathrm{RecO}$ and $\mathrm{RecR}$ functions that also catalyze single-strand annealing (Alonso et al., 1992; Manfredi et al., 2008).

\section{AUTHOR CONTRIBUTIONS}

AV-R, ML-S, AQ-O, and SA: performed the experiments; AV-R, AS, and SA: analyzed data; SA: conceived the project, integrated the results and wrote the paper.

\section{FUNDING}

This work was partially supported by Spanish grants BFU201239879-C02-02 and BFU2015-67065-P from MINECO to SA, and PathoBactEvol (ANR-12-ADAP-0018) from ANR to AS.

\section{ACKNOWLEDGMENTS}

We thank J. C. Alonso (CNB-CSIC, Spain) for providing us with pUB110 and pHP13 plasmid derivatives, and for critically reading this manuscript. Plasmid pNDH33 was kindly provided by Wolfgang Schumann (University of Bayreuth, Germany).

\section{SUPPLEMENTARY MATERIAL}

The Supplementary Material for this article can be found online at: http://journal.frontiersin.org/article/10.3389/fmicb. 2017.01816/full\#supplementary-material 


\section{REFERENCES}

Alonso, J. C., Luder, G., and Trautner, T. A. (1986). Requirements for the formation of plasmid-transducing particles of Bacillus subtilis bacteriophage SPP1. EMBO J. 5, 3723-3728.

Alonso, J. C., Luder, G., and Trautner, T. A. (1992). Intramolecular homologous recombination in Bacillus subtilis 168. Mol. Gen. Genet. 236, 60-64.

Alonso, J. C., Stiege, C. A., Tailor, R. H., and Viret, J. F. (1988). Functional analysis of the dna (Ts) mutants of Bacillus subtilis: plasmid pUB110 replication as a model system. Mol. Gen. Genet. 214, 482-489. doi: 10.1007/BF003 30484

Alonso, J. C., Tavares, P., Lurz, R., and Trautner, T. A. (2006). "Bacteriophage SPP1," in The Bacteriophages, ed. R. Calendar (New York, NY: Oxford University Press), 18.

Alonso, J. C., and Trautner, T. A. (1985). A gene controlling segregation of the Bacillus subtilis plasmid pC194. Mol. Gen. Genet. 198, 427-431. doi: 10.1007/ BF00332934

Ander, M., Subramaniam, S., Fahmy, K., Stewart, A. F., and Schaffer, E. (2015). A single-strand snnealing protein clamps DNA to detect and secure homology. PLOS Biol. 13:e1002213. doi: 10.1371/journal.pbio.1002213

Ayora, S., Missich, R., Mesa, P., Lurz, R., Yang, S., Egelman, E. H., et al. (2002). Homologous-pairing activity of the Bacillus subtilis bacteriophage SPP1 replication protein G35P. J. Biol. Chem. 277, 35969-35979. doi: 10.1074/jbc. M20446720

Ayora, S., Stasiak, A., and Alonso, J. C. (1999). The Bacillus subtilis bacteriophage SPP1 G39P delivers and activates the G40P DNA helicase upon interacting with the G38P-bound replication origin. J. Mol. Biol. 288, 71-85. doi: 10.1006/jmbi. 1999.2662

Bravo, A., and Alonso, J. C. (1990). The generation of concatemeric plasmid DNA in Bacillus subtilis as a consequence of bacteriophage SPP1 infection. Nucleic Acids Res. 18, 4651-4657. doi: 10.1093/nar/18.16.4651

Bravo, A., Alonso, J. C., and Trautner, T. A. (1990). Functional analysis of the Bacillus subtilis bacteriophage SPP1 pac site. Nucleic Acids Res. 18, 2881-2886. doi: 10.1093/nar/18.10.2881

Brown-Jaque, M., Calero-Caceres, W., and Muniesa, M. (2015). Transfer of antibiotic-resistance genes via phage-related mobile elements. Plasmid 79, 1-7. doi: 10.1016/j.plasmid.2015.01.001

Brussow, H., Canchaya, C., and Hardt, W. D. (2004). Phages and the evolution of bacterial pathogens: from genomic rearrangements to lysogenic conversion. Microbiol. Mol. Biol. Rev. 68, 560-602. doi: 10.1128/MMBR.68.3.560-602.2004

Burger, K. J., and Trautner, T. A. (1978). Specific labelling of replicating SPP1 DNA: analysis of viral DNA synthesis and identification of phage DNA-genes. Mol. Gen. Genet. 166, 277-285.

Camacho, A. G., Gual, A., Lurz, R., Tavares, P., and Alonso, J. C. (2003). Bacillus subtilis bacteriophage SPP1 DNA packaging motor requires terminase and portal proteins. J. Biol. Chem. 278, 23251-23259. doi: 10.1074/jbc.M301805200

Canchaya, C., Fournous, G., Chibani-Chennoufi, S., Dillmann, M. L., and Brussow, H. (2003). Phage as agents of lateral gene transfer. Curr. Opin. Microbiol. 6, 417-424. doi: 10.1016/S1369-5274(03)00086-9

Canosi, U., Luder, G., and Trautner, T. A. (1982). SPP1-mediated plasmid transduction. J. Virol. 44, 431-436.

Ceglowski, P., Boitsov, A., Chai, S., and Alonso, J. C. (1993a). Analysis of the stabilization system of pSM19035-derived plasmid pBT233 in Bacillus subtilis. Gene 136, 1-12.

Ceglowski, P., Boitsov, A., Karamyan, N., Chai, S., and Alonso, J. C. (1993b). Characterization of the effectors required for stable inheritance of Streptococcus pyogenes pSM19035-derived plasmids in Bacillus subtilis. Mol. Gen. Genet. 241, 579-585.

Ceglowski, P., Lurz, R., and Alonso, J. C. (1993c). Functional analysis of pSM19035derived replicons in Bacillus subtilis. FEMS Microbiol. Lett. 109, 145-150.

Chai, S., Bravo, A., Luder, G., Nedlin, A., Trautner, T. A., and Alonso, J. C. (1992). Molecular analysis of the Bacillus subtilis bacteriophage SPP1 region encompassing genes 1 to 6 . The products of gene 1 and gene 2 are required for pac cleavage. J. Mol. Biol. 224, 87-102. doi: 10.1016/0022-2836(92)90578-8

Chai, S., Lurz, R., and Alonso, J. C. (1995). The small subunit of the terminase enzyme of Bacillus subtilis bacteriophage SPP1 forms a specialized nucleoprotein complex with the packaging initiation region. J. Mol. Biol. 252, 386-398. doi: 10.1006/jmbi.1995.0505
Chai, S., Szepan, U., and Alonso, J. C. (1997). Bacillus subtilis bacteriophage SPP1 terminase has a dual activity: it is required for the packaging initiation and represses its own synthesis. Gene 184, 251-256. doi: 10.1016/S0378-1119(96) 00609-9

Chai, S., Szepan, U., Luder, G., Trautner, T. A., and Alonso, J. C. (1993). Sequence analysis of the left end of the Bacillus subtilis bacteriophage SPP1 genome. Gene 129, 41-49. doi: 10.1016/0378-1119(93) 90694-X

Cohen, A., and Clark, A. J. (1986). Synthesis of linear plasmid multimers in Escherichia coli K-12. J. Bacteriol. 167, 327-335. doi: 10.1128/jb.167.1.327-335. 1986

Datta, S., Costantino, N., Zhou, X., and Court, D. L. (2008). Identification and analysis of recombineering functions from Gram-negative and Grampositive bacteria and their phages. Proc. Natl. Acad. Sci. U.S.A. 105, 1626-1631. doi: 10.1073/pnas.0709089105

De Paepe, M., Hutinet, G., Son, O., Amarir-Bouhram, J., Schbath, S., and Petit, M. A. (2014). Temperate phages acquire DNA from defective prophages by relaxed homologous recombination: the role of Rad52-like recombinases. PLOS Genet. 10:e1004181. doi: 10.1371/journal.pgen.1004181

Deichelbohrer, I., Alonso, J. C., Luder, G., and Trautner, T. A. (1985). Plasmid transduction by Bacillus subtilis bacteriophage SPP1: effects of DNA homology between plasmid and bacteriophage. J. Bacteriol. 162, 1238-1243.

Delattre, H., Souiai, O., Fagoonee, K., Guerois, R., and Petit, M. A. (2016). Phagonaute: a web-based interface for phage synteny browsing and protein function prediction. Virology 496, 42-50. doi: 10.1016/j.virol.2016.05.007

Espinosa, M., del Solar, G., Rojo, F., and Alonso, J. C. (1995). Plasmid rolling circle replication and its control. FEMS Microbiol. Lett. 130, 111-120. doi: 10.1111/j. 1574-6968.1995.tb07707.x

Ferrari, E., Canosi, U., Galizzi, A., and Mazza, G. (1978). Studies on transduction process by SPP1 phage. J. Gen. Virol. 41, 563-572. doi: 10.1099/0022-1317-413-563

Fricker, A. D., and Peters, J. E. (2014). Vulnerabilities on the lagging-strand template: opportunities for mobile elements. Annu. Rev. Genet. 48, 167-186. doi: 10.1146/annurev-genet-120213-092046

Giovanetti, E., Brenciani, A., Morroni, G., Tiberi, E., Pasquaroli, S., Mingoia, M., et al. (2014). Transduction of the Streptococcus pyogenes bacteriophage Phim46.1, carrying resistance genes $\operatorname{mef}(\mathrm{A})$ and tet $(\mathrm{O})$, to other Streptococcus species. Front. Microbiol. 5:746. doi: 10.3389/fmicb.2014.00746

Gual, A., Camacho, A. G., and Alonso, J. C. (2000). Functional analysis of the terminase large subunit, G2P, of Bacillus subtilis bacteriophage SPP1. J. Biol. Chem. 275, 35311-35319. doi: 10.1074/jbc.M004309200

Haima, P., Bron, S., and Venema, G. (1987). The effect of restriction on shotgun cloning and plasmid stability in Bacillus subtilis Marburg. Mol. Gen. Genet. 209, 335-342. doi: 10.1007/BF00329663

Horinouchi, S., and Weisblum, B. (1982). Nucleotide sequence and functional map of pC194, a plasmid that specifies inducible chloramphenicol resistance. J. Bacteriol. 150, 815-825.

Ikeda, H., and Tomizawa, J. I. (1965). Transducing fragments in generalized transduction by phage P1. I. Molecular origin of the fragments. J. Mol. Biol. 14, 85-109. doi: 10.1016/S0022-2836(65)80232-7

Kenzaka, T., Tani, K., and Nasu, M. (2010). High-frequency phage-mediated gene transfer in freshwater environments determined at single-cell level. ISME J. 4, 648-659. doi: 10.1038/ismej.2009.145

Khan, S. A. (2005). Plasmid rolling-circle replication: highlights of two decades of research. Plasmid 53, 126-136. doi: 10.1016/j.plasmid.2004.12.008

Kidane, D., Carrasco, B., Manfredi, C., Rothmaier, K., Ayora, S., Tadesse, S., et al. (2009). Evidence for different pathways during horizontal gene transfer in competent Bacillus subtilis cells. PLOS Genet. 5:e1000630. doi: 10.1371/journal. pgen. 1000630

Kreuzer, K. N. (2000). Recombination-dependent DNA replication in phage T4. Trends Biochem. Sci. 25, 165-173. doi: 10.1016/S0968-0004(00)01559-0

Kreuzer, K. N., Yap, W. Y., Menkens, A. E., and Engman, H. W. (1988). Recombination-dependent replication of plasmids during bacteriophage T4 infection. J. Biol. Chem. 263, 11366-11373.

Lajoie, M. J., Gregg, C. J., Mosberg, J. A., Washington, G. C., and Church, G. M. (2012). Manipulating replisome dynamics to enhance lambda Red-mediated multiplex genome engineering. Nucleic Acids Res. 40:e170. doi: 10.1093/nar/ gks751 
Lennox, E. S. (1955). Transduction of linked genetic characters of the host by bacteriophage P1. Virology 1, 190-206. doi: 10.1016/0042-6822(55)90016-7

Leonhardt, H. (1990). Identification of a low-copy-number mutation within the pUB110 replicon and its effect on plasmid stability in Bacillus subtilis. Gene 94, 121-124. doi: 10.1016/0378-1119(90)90477-9

Leonhardt, H., Lurz, R., and Alonso, J. C. (1991). Physical and biochemical characterization of recombination-dependent synthesis of linear plasmid multimers in Bacillus subtilis. Nucleic Acids Res. 19, 497-503. doi: 10.1093/nar/ 19.3.497

Lo Piano, A., Martinez-Jimenez, M. I., Zecchi, L., and Ayora, S. (2011). Recombination-dependent concatemeric viral DNA replication. Virus Res. 160, 1-14. doi: 10.1016/j.virusres.2011.06.009

Lopes, A., Amarir-Bouhram, J., Faure, G., Petit, M. A., and Guerois, R. (2010). Detection of novel recombinases in bacteriophage genomes unveils Rad52, Rad51 and Gp2.5 remote homologs. Nucleic Acids Res. 38, 3952-3962. doi: 10.1093/nar/gkq096

Manfredi, C., Carrasco, B., Ayora, S., and Alonso, J. C. (2008). Bacillus subtilis RecO nucleates RecA onto SsbA-coated single-stranded DNA. J. Biol. Chem. 283, 24837-24847. doi: 10.1074/jbc.M802002200

Mann, B. A., and Slauch, J. M. (1997). Transduction of low-copy number plasmids by bacteriophage P22. Genetics 146, 447-456.

Martinez-Jimenez, M. I., Alonso, J. C., and Ayora, S. (2005). Bacillus subtilis bacteriophage SPP1-encoded gene 34.1 product is a recombination-dependent DNA replication protein. J. Mol. Biol. 351, 1007-1019. doi: 10.1016/j.jmb.2005. 06.064

Martinez-Jimenez, M. I., Mesa, P., and Alonso, J. C. (2002). Bacillus subtilis tau subunit of DNA polymerase III interacts with bacteriophage SPP1 replicative DNA helicase G40P. Nucleic Acids Res. 30, 5056-5064. doi: 10.1093/nar/ gkf650

Maslanova, I., Doskar, J., Varga, M., Kuntova, L., Muzik, J., Maluskova, D., et al. (2013). Bacteriophages of Staphylococcus aureus efficiently package various bacterial genes and mobile genetic elements including SCCmec with different frequencies. Environ. Microbiol. Rep. 5, 66-73. doi: 10.1111/j.1758-2229.2012. 00378.x

Menouni, R., Hutinet, G., Petit, M. A., and Ansaldi, M. (2015). Bacterial genome remodeling through bacteriophage recombination. FEMS Microbiol. Lett. 362, 1-10. doi: 10.1093/femsle/fnu022

Missich, R., Weise, F., Chai, S., Lurz, R., Pedre, X., and Alonso, J. C. (1997). The replisome organizer (G38P) of Bacillus subtilis bacteriophage SPP1 forms specialized nucleoprotein complexes with two discrete distant regions of the SPP1 genome. J. Mol. Biol. 270, 50-64. doi: 10.1006/jmbi.1997. 1060

Mosberg, J. A., Lajoie, M. J., and Church, G. M. (2010). Lambda red recombineering in Escherichia coli occurs through a fully single-stranded intermediate. Genetics 186, 791-799. doi: 10.1534/genetics.110.120782

Mosig, G., Gewin, J., Luder, A., Colowick, N., and Vo, D. (2001). Two recombination-dependent DNA replication pathways of bacteriophage T4, and their roles in mutagenesis and horizontal gene transfer. Proc. Natl. Acad. Sci. U.S.A. 98, 8306-8311. doi: 10.1073/pnas. 131007398

Neamah, M. M., Mir-Sanchis, I., Lopez-Sanz, M., Acosta, S., Baquedano, I., Haag, A. F., et al. (2017). Sak and Sak4 recombinases are required for bacteriophage replication in Staphylococcus aureus. Nucleic Acids Res. 45, 6507-6519. doi: 10.1093/nar/gkx308

Nguyen, H. D., Nguyen, Q. A., Ferreira, R. C., Ferreira, L. C., Tran, L. T., and Schumann, W. (2005). Construction of plasmid-based expression vectors for Bacillus subtilis exhibiting full structural stability. Plasmid 54, 241-248. doi: 10.1016/j.plasmid.2005.05.001

Oliveira, L., Alonso, J. C., and Tavares, P. (2005). A defined in vitro system for DNA packaging by the bacteriophage SPP1: insights into the headful packaging mechanism. J. Mol. Biol. 353, 529-539. doi: 10.1016/j.jmb.2005.08.063

Oliveira, L., Tavares, P., and Alonso, J. C. (2013). Headful DNA packaging: bacteriophage SPP1 as a model system. Virus Res. 173, 247-259. doi: 10.1016/j. virusres.2013.01.021

Orbach, M. J., and Jackson, E. N. (1982). Transfer of chimeric plasmids among Salmonella typhimurium strains by P22 transduction. J. Bacteriol. 149, 985-994.

Pedre, X., Weise, F., Chai, S., Luder, G., and Alonso, J. C. (1994). Analysis of cis and trans acting elements required for the initiation of DNA replication in the Bacillus subtilis bacteriophage SPP1. J. Mol. Biol. 236, 1324-1340. doi: 10.1016/0022-2836(94)90061-2

Penades, J. R., Chen, J., Quiles-Puchalt, N., Carpena, N., and Novick, R. P. (2015). Bacteriophage-mediated spread of bacterial virulence genes. Curr. Opin. Microbiol. 23, 171-178. doi: 10.1016/j.mib.2014.11.019

Phan, T. T., Nguyen, H. D., and Schumann, W. (2006). Novel plasmid-based expression vectors for intra- and extracellular production of recombinant proteins in Bacillus subtilis. Protein Expr. Purif. 46, 189-195. doi: 10.1016/j.pep. 2005.07.005

Ruzin, A., Lindsay, J., and Novick, R. P. (2001). Molecular genetics of SaPI1a mobile pathogenicity island in Staphylococcus aureus. Mol. Microbiol. 41, 365-377. doi: 10.1046/j.1365-2958.2001.02488.x

Scaltriti, E., Launay, H., Genois, M. M., Bron, P., Rivetti, C., Grolli, S., et al. (2011). Lactococcal phage p2 ORF35-Sak3 is an ATPase involved in DNA recombination and AbiK mechanism. Mol. Microbiol. 80, 102-116. doi: 10.1111/j.1365-2958.2011.07561.x

Schmidt, C., and Schmieger, H. (1984). Selective transduction of recombinant plasmids with cloned pac sites by Salmonella phage P22. Mol. Gen. Genet. 196, 123-128. doi: 10.1007/BF00334103

Schmieger, H. (1984). pac sites are indispensable for in vivo packaging of DNA by phage P22. Mol. Gen. Genet. 195, 252-255. doi: 10.1007/BF00332755

Schumann, W. (2007). Production of recombinant proteins in Bacillus subtilis. Adv. Appl. Microbiol. 62, 137-189. doi: 10.1016/S0065-2164(07)62006-1

Seco, E. M., and Ayora, S. (2017). Bacillus subtilis DNA polymerases, PolC and DnaE, are required for both leading and lagging strand synthesis in SPP1 origindependent DNA replication. Nucleic Acids Res. 45, 8302-8313. doi: 10.1093/nar/ gkx493

Seco, E. M., Zinder, J. C., Manhart, C. M., Lo Piano, A., McHenry, C. S., and Ayora, S. (2013). Bacteriophage SPP1 DNA replication strategies promote viral and disable host replication in vitro. Nucleic Acids Res. 41, 1711-1721. doi: 10.1093/nar/gks1290

Silberstein, Z., and Cohen, A. (1987). Synthesis of linear multimers of OriC and pBR322 derivatives in Escherichia coli K-12: role of recombination and replication functions. J. Bacteriol. 169, 3131-3137. doi: 10.1128/jb.169.7.31313137.1987

Sun, Z., Deng, A., Hu, T., Wu, J., Sun, Q., Bai, H., et al. (2015). A high-efficiency recombineering system with PCR-based ssDNA in Bacillus subtilis mediated by the native phage recombinase GP35. Appl. Microbiol. Biotechnol. 99, 5151-5162. doi: 10.1007/s00253-015-6485-5

Szczepanska, A. K. (2009). Bacteriophage-encoded functions engaged in initiation of homologous recombination events. Crit. Rev. Microbiol. 35, 197-220. doi: 10.1080/10408410902983129

te Riele, H., Michel, B., and Ehrlich, S. D. (1986). Single-stranded plasmid DNA in Bacillus subtilis and Staphylococcus aureus. Proc. Natl. Acad. Sci. U.S.A. 83, 2541-2545. doi: 10.1073/pnas.83.8.2541

Titok, M. A., Chapuis, J., Selezneva, Y. V., Lagodich, A. V., Prokulevich, V. A., Ehrlich, S. D., et al. (2003). Bacillus subtilis soil isolates: plasmid replicon analysis and construction of a new theta-replicating vector. Plasmid 49, 53-62. doi: 10.1016/S0147-619X(02)00109-9

Touchon, M., Moura de Sousa, J. A., and Rocha, E. P. (2017). Embracing the enemy: the diversification of microbial gene repertoires by phage-mediated horizontal gene transfer. Curr. Opin. Microbiol. 38, 66-73. doi: 10.1016/j.mib.2017.04.010

Tzipilevich, E., Habusha, M., and Ben-Yehuda, S. (2017). Acquisition of phage sensitivity by bacteria through exchange of phage receptors. Cell 168, 186e-199e. doi: 10.1016/j.cell.2016.12.003

van Kessel, J. C., and Hatfull, G. F. (2008). Efficient point mutagenesis in mycobacteria using single-stranded DNA recombineering: characterization of antimycobacterial drug targets. Mol. Microbiol. 67, 1094-1107. doi: 10.1111/j. 1365-2958.2008.06109.x

Viret, J. F., and Alonso, J. C. (1987). Generation of linear multigenome-length plasmid molecules in Bacillus subtilis. Nucleic Acids Res. 15, 6349-6367. doi: $10.1093 / \mathrm{nar} / 15.16 .6349$

Viret, J. F., and Alonso, J. C. (1988). A DNA sequence outside the pUB110 minimal replicon is required for normal replication in Bacillus subtilis. Nucleic Acids Res. 16, 4389-4406. doi: 10.1093/nar/16.10.4389

Viret, J. F., Bravo, A., and Alonso, J. C. (1991). Recombination-dependent concatemeric plasmid replication. Microbiol. Rev. 55, 675-683. 
Wang, J. D., Rokop, M. E., Barker, M. M., Hanson, N. R., and Grossman, A. D. (2004). Multicopy plasmids affect replisome positioning in Bacillus subtilis. J. Bacteriol. 186, 7084-7090. doi: 10.1128/JB.186.21.7084-7090. 2004

Winstel, V., Kuhner, P., Krismer, B., Peschel, A., and Rohde, H. (2015). Transfer of plasmid DNA to clinical coagulase-negative staphylococcal pathogens by using a unique bacteriophage. Appl. Environ. Microbiol. 81, 2481-2488. doi: 10.1128/AEM.04190-14

Yasbin, R. E., and Young, F. E. (1974). Transduction in Bacillus subtilis by bacteriophage SPP1. J. Virol. 14, 1343-1348.

Zecchi, L., Lo Piano, A., Suzuki, Y., Canas, C., Takeyasu, K., and Ayora, S. (2012). Characterization of the Holliday junction resolving enzyme encoded by the Bacillus subtilis bacteriophage SPP1. PLOS ONE 7:e48440. doi: 10.1371/journal. pone. 0048440
Zinder, N. D., and Lederberg, J. (1952). Genetic exchange in Salmonella. J. Bacteriol. 64, 679-699.

Conflict of Interest Statement: The authors declare that the research was conducted in the absence of any commercial or financial relationships that could be construed as a potential conflict of interest.

Copyright (c) 2017 Valero-Rello, López-Sanz, Quevedo-Olmos, Sorokin and Ayora. This is an open-access article distributed under the terms of the Creative Commons Attribution License (CC BY). The use, distribution or reproduction in other forums is permitted, provided the original author(s) or licensor are credited and that the original publication in this journal is cited, in accordance with accepted academic practice. No use, distribution or reproduction is permitted which does not comply with these terms. 